\title{
EDITORIAL
}

\section{CIÊNCIA E A COVID-19}

As epidemias acompanham a humanidade desde tempos remotos, algumas como a peste negra, gripe espanhola e a varíola foram responsáveis por numerosas mortes em todo o mundo. Outras doenças infecciosas como a tuberculose, leishmaniose, malária igualmente muito antigas ainda continuam causando milhares de mortes nos dias de hoje. Neste cenário de antigas epidemias, já controladas ou ainda muito presentes entre a humanidade, no final de dezembro de 2019 foi identificado um novo coronavírus SARSCoV-2 (Severe Acute Respiratory Syndrome Coronavirus 2) causando uma nova pandemia chamada de COVID-19 (Coronavirus Disease 2019). O novo vírus, com alta taxa de transmissibilidade, se tornou um enorme desafio global de saúde. Como ocorre com a maioria das doenças infecciosas, a COVID-19 atinge a população de forma assimétrica, sendo mais dura com idosos, cardiopatas, diabéticos e obesos. Além de fatores de risco para formas mais graves como a faixa etária e as comorbidades, a COVID19, que no início teve maior prevalência nas camadas mais ricas da sociedade, agora direciona-se para as populações com maior vulnerabilidade social, especialmente nos países em desenvolvimento. Apesar da volumosa quantidade de informações científicas sobre a doença e o novo coronavírus geradas nestes cinco meses de pandemia, muitas perguntas importantes ainda não foram plenamente respondidas, como por exemplo: Qual a história evolutiva do vírus? Qual o papel antropogênico no surgimento do novo vírus? Qual a fisiopatologia da COVID-19? Qual a efetividade dos fármacos off label que estão sendo usados nos protocolos atuais? Quais novos antivirais poderão ser efetivos no tratamento? Qual o eventual papel da BCG na atenuação da doença? Qual o atual portfolio de vacinas para COVID-19? Como o papel das mídias sociais na pandemia? Qual o impacto psicológico do isolamento social? Como tornar-se soberano na produção de insumos e equipamentos de saúde?

Estas e outras questões somente poderão ser respondidas ao longo do tempo através da pesquisa e a geração de evidências científicas. A ciência é um patrimônio da sociedade gerando melhoria da qualidade de vida e promovendo a soberania do país. Mas a ciência não pode ter um conceito prêt-à-porter, o investimento em ciência deve ser robusto e constante, os resultados científicos necessitam de tempo e recursos humanos e financeiros. Assim como a vida, as epidemias somente são entendidas olhando para trás.

Life can only be understood backwards; but it must be lived forwards. Soren Kierkegaard

Prof. Dr. Pedro Eduardo Almeida da Silva

Professor Titular de Microbiologia Médica Vice-Presidente da REDE-TB

Programa de Pós-graduação em Ciências da Saúde

Faculdade de Medicina

Universidade Federal do Rio Grande 